\title{
OS ENCONTROS NACIONAIS DA INDÚSTRIA (ENAIS): A BURGUESIA INDUSTRIAL AGINDO COMO FORÇA SOCIAL E COLETIVAMENTE ORGANIZADA
}

\author{
Marco André Cadoná \\ Universidade de Santa Cruz do Sul - UNISC - Brasil
}

\section{Resumo}

$\mathrm{Na}$ bibliografia que analisa a atuação política da burguesia industrial no Brasil a partir da democratização do País (1980), um dos pontos de discordância está relacionado com a capacidade das lideranças políticas dessa fração burguesa no País em aglutinar a complexidade dos interesses industriais em torno de uma agenda política comum. Neste artigo, a mobilização da Federação das Indústrias do Estado do Rio Grande do Sul, visando à participação nos Encontros Nacionais da Indústria promovidos pela Confederação Nacional da Indústria durante o segundo governo Lula (2007 - 2010), é tomada como referência empírica para a análise da capacidade política que as entidades de representação da burguesia industrial no Brasil têm demonstrado para aglutinar o segmento enquanto força social e coletivamente organizada e viabilizar ações conjuntas em torno de objetivos comuns.

Palavras-chave: Burguesia industrial no Rio Grande do Sul, atuação classista, Encontros Nacionais da Indústria.

\section{Introdução:}

\begin{abstract}
O evento mostra força e união, e nosso peso junto às autoridades que reconhecem a CNI como a entidade que representa os industriais brasileiros. No estado, sempre promovemos eventos para mostrar essa ligação e a importância de ter uma confederação, uma federação e sindicatos atuantes e fortes (TIGRE, 2008).
\end{abstract}

Na citação acima, o presidente da Federação das Indústrias do Estado do Rio Grande do Sul (FIERGS) no período entre 2006 e 2011, industrial Paulo Fernandes Tigre, comentando a participação dos industriais gaúchos no III Encontro Nacional da Indústria, realizado em Brasília nos dias 28 e 29 de outubro de 2008, ressalta a importância da articulação da burguesia industrial no Brasil enquanto força social e coletivamente organizada visando a defesa de seus interesses de classe.

Realizado anualmente desde 2006, o Encontro Nacional da Indústria (ENAI) tornouse, desde então, um dos principais eventos políticos da burguesia industrial no Brasil. Organizado pela Confederação Nacional da Indústria (CNI) e contando com a participação de todas as federações estaduais da indústria no País, o evento tem reunido lideranças industriais de todo o País, especialistas de diferentes áreas de interesse da indústria, autoridades 
governamentais, em momentos não somente de discussões e de reflexões sobre temas de interesse da burguesia industrial, mas, também, de construção de consensos em tornos de pautas comuns e de definição de estratégias políticas visando a defesa dessas pautas nas instâncias de decisão do Estado brasileiro.

Neste artigo, a análise da participação da burguesia industrial do Rio Grande do Sul nos ENAIs realizados durante o segundo governo de Luís Inácio Lula da Silva (2007 - 2010) serve de pano de fundo para uma reflexão acerca da capacidade das "instituições tradicionais" de representação dos interesses da indústria no Brasil (em especial, as federações estaduais e a CNI) em se colocarem como "elite orgânica" da burguesia industrial, constituindo-se como agentes coletivos com capacidade de "visualizar objetivos globais" (e capazes de aglutinar os interesses dos diferentes setores e segmentos que compõem a estrutura industrial no País) e de "operacionalizar a condução das ações requeridas em todos os campos para alcançar suas metas" (DREIFUSS, 1986, p. 23).

Ao argumentar em favor da proposição indicada no parágrafo anterior, pretende-se contribuir para um importante debate presente na bibliografia que analisa a atuação política da burguesia industrial no Brasil a partir do processo de democratização, na década de 1980. Tratase de um ponto de discordância entre os pesquisadores e que está relacionado com a capacidade das lideranças políticas da burguesia industrial em aglutinar a complexidade dos interesses industriais no País em torno de uma agenda política comum. Para alguns pesquisadores, já a partir daquela década a burguesia industrial demonstrou grande capacidade em atuar como força social e coletivamente organizada, liderada por entidades de representação que demonstraram habilidade política para viabilizar uma ação conjunta em torno de objetivos comuns (MANCUSO \& OLIVEIRA, 2006; CADONÁ, 2009; FARIA \& MELO, 2013); para outros pesquisadores, no entanto, a atuação política da burguesia industrial a partir daquela década tem se caracterizado pela "fragmentação excessiva", o que, agravado pela inexistência de associações empresariais de maior abrangência e capazes de organizar a ação coletiva, inviabiliza uma ação conjunta em torno de objetivos comuns (DINIZ \& BOSCHI, 2004; DINIZ \& PEREIRA, 2008).

\section{A articulação preparatória para o ENAI: os Encontros Estaduais da Indústria no Rio Grande do Sul}

Desde seu surgimento, os Encontros Nacionais da Indústria são precedidos por mobilizações estaduais, organizadas pelas federações estaduais da indústria com o objetivo de 
impulsionar debates e reflexões a partir das estruturas estaduais da indústria, mas, também, a participação no evento nacional. No caso do Rio Grande do Sul e tomando como referência o período que compreende o segundo governo de Luís Inácio Lula da Silva (2007 - 2010), as diretorias da FIERGS estiveram sempre atentas para a importância dos ENAIs e, inclusive, num trabalho de preparação para aquele evento, organizaram anualmente Encontros Estaduais da Indústria que proporcionaram espaços de articulação política, em diferentes regiões do Rio Grande do Sul, e a definição de pautas conjunturais de interesses (construção de diagnósticos da indústria no estado, definição de prioridades em pautas de reivindicações junto aos governos). É ilustrativa, nesse sentido, a manifestação do presidente da FIERGS, chamando os industriais gaúchos para a mobilização que visava o II ENAI, realizado em 2007:

\footnotetext{
Mais uma vez as Federações e Sindicatos industriais de todo o País terão a oportunidade de unir suas ideias e propostas para encaminhar, reencaminhar, corrigir e prospectar os rumos do desenvolvimento brasileiro.

Mas o trabalho começa antes. E a FIERGS promoverá um Encontro Estadual, dia 2 de outubro, para consolidar a participação da indústria gaúcha naquele evento. Temos que mostrar nossa força e ocupar o espaço que é oferecido (TIGRE, 2007).
}

A manifestação do presidente da FIERGS é expressiva, também, de um conjunto de ações que a entidade realizou, anualmente, visando articular a burguesia industrial no Rio Grande do Sul primeiro para o encontro estadual e, por fim, para a participação nos encontros nacionais.

Nessa direção, há de se considerar, em primeiro lugar, a articulação dos próprios espaços de estudos e de conscientização que a estrutura da FIERGS comporta. Desde a década de 1980, com um trabalho de "modernização" durante a década de 1990, a entidade estruturou Conselhos Temáticos e Comissões Setoriais que envolvem diretamente (na gestão política da entidade) lideranças industriais que representam todas as regiões do estado gaúcho e todos os setores da indústria sul-rio-grandense (CADONÁ, 2009). Através dessa estrutura, a FIERGS mobiliza uma ampla intelligentsia, que é formada por lideranças industriais, mas, também, por funcionários, técnicos e acadêmicos (contratados como assalariados ou, então, prestando assessorias), dando operacionalidade e sustentação política e ideológica às atividades e aos objetivos da entidade. ${ }^{1}$

\footnotetext{
${ }^{1}$ Atualmente, a FIERGS possui treze Conselhos Temáticos: Conselho de Economia e Assuntos Estratégicos; Conselho de Agroindústria; Conselho de Assuntos Tributários e Legais; Conselho de Relações Internacionais e Comércio Exterior; Conselho de Infraestrutura; Conselho do Meio Ambiente; Conselho de Pequena e Média Indústria; Conselho de Responsabilidade Social e Cidadania; Conselho de Relações de Trabalho e Previdência Social; Conselho de Inovação e Tecnologia; Conselho de Articulação Parlamentar; Conselho de Áreas Temáticas Setoriais; Conselho de Representações Externas. In: www.fiergs.org.br.
} 
Como afirma René Dreifuss, poder significa a capacidade de exercer uma ação política de forma ininterrupta, "num movimento de pinças, envolvente, político-ideológico, sempre reproduzindo e ampliando as bases de atuação para conquistar, salvaguardar e consolidar posições" (DREIFUSS, 1986, p. 22). Com a estrutura organizacional montada, a FIERGS dispõe de uma grande quantidade de "intelectuais orgânicos" (entre técnicos e lideranças industriais), diariamente empenhados em tornar eficaz a ação política da entidade, dotando suas lideranças de informações, estudos, análises, documentos, estratégias de ação, organização e, portanto, instrumentalizando a entidade para uma ação premeditada e com intencionalidade planejada. E, evidentemente, durante os períodos preparatórios para os encontros estaduais da indústria realizados a partir de 2007, a estrutura organizacional da entidade passou a ser acionada, numa perspectiva de construção de diagnósticos sobre as condições de desenvolvimento da indústria no Rio Grande do Sul, mas, também, de pautas de reivindicações para serem apresentadas às autoridades governamentais.

É importante destacar, também, a capacidade de articulação da FIERGS nas diferentes regiões do estado sul-rio-grandense. Desde a década de 1990, aliás, a FIERGS possui um trabalho de "interiorização", visando intensificar sua presença junto a entidades e a lideranças empresariais de todo o território gaúcho, articulando coletivamente o setor industrial no estado e construindo pautas comuns de atuação e de reivindicações. Em 2007, por exemplo, ou o presidente da FIERGS ou dirigentes da entidade estiveram em diferentes municípios gaúchos, ocasiões aproveitadas para discussões sobre temas de interesse dos industriais locais e estaduais, mas, também, de articulação política junto a representantes políticos (municipais e estaduais, dos legislativos e dos executivos) para a defesa de seus interesses de classe. No período de preparação para o encontro estadual da indústria daquele ano, inclusive, o próprio presidente da FIERGS aproveitou um fórum realizado com vice-presidentes regionais da entidade (representando diferentes regiões no território gaúcho) para discutir a importância da participação no evento (FIERGS, 2007a).

Toda a articulação da FIERGS para a realização do Encontro Estadual da Indústria (preparatório para o II ENAI) foi exitosa, considerando que no dia de sua realização (02 de outubro de 2007), representantes de sindicatos industriais de diferentes regiões do Rio Grande do Sul participaram das discussões e da elaboração de um documento que contemplou os temas prioritários da indústria gaúcha no Encontro Nacional da Indústria: licenciamento e compensação ambiental; lei geral, políticas e programas de apoio às MPEs (Médias e Pequenas Empresas); reforma trabalhista; infraestrutura; reforma tributária e previdenciária; política industrial, tecnológica e de comércio exterior (IDEM, 2007b). E o resultado da mobilização da 
entidade, sob o ponto de vista da participação no Encontro Nacional, se concretizou numa comitiva de setenta e um líderes industriais do Rio Grande do Sul, num evento que reuniu, em Brasília, mil duzentas lideranças industriais de todo o País (IDEM, 2007c).

Após o Encontro Nacional, as lideranças da FIERGS socializaram os resultados com as entidades representativas da indústria no Rio Grande do Sul. Assim, por exemplo, em novembro de 2007 a entidade realizou um Fórum dos Vices Presidentes Regionais, ocasião na qual os resultados do II ENAI foram discutidos, enfatizando-se a necessidade dos Sindicatos orientarem suas ações a partir das definições tomadas naquele encontro. (FIERGS, 2007d). De igual forma, durante os meses de novembro e de dezembro de 2007, as lideranças da FIERGS, em suas ações realizadas dentro do projeto de "interiorização" da entidade, também socializaram e discutiram os resultados do II ENAI, sempre na perspectiva de afirmar consensos e a unidade em torno de uma agenda política definida a partir daquele Encontro.

Nos anos seguintes do segundo governo Lula, quando ocorreram o terceiro (2008), o quarto (2009) e o quinto (2010) ENAIs, a FIERGS manteve as mobilizações políticas, realizando encontros estaduais preparatórios e impulsionando a participação dos sindicatos e demais entidades representativas dos interesses da indústria no Rio Grande do Sul.

Nessa direção, em 2008, o encontro estadual reuniu novamente lideranças na Sede da FIERGS no final de agosto, quando definiram uma "agenda industrial gaúcha" para ser levada no III ENAI (realizado nos dias 28 e 29 de outubro daquele ano), formada por 30 propostas articuladas em torno de cinco eixos: inovação e produtividade na indústria; sistema trabalhista e impactos na competividade industrial; sistema tributário e os desafios para a indústria; competitividade sistêmica - infraestrutura e meio ambiente; inserção internacional da indústria brasileira (IDEM, 2008). A comitiva do Rio Grande do Sul no III ENAI foi formada por 45 lideranças. Após a sua realização, o presidente da FIERGS manifestou-se em relação ao III ENAI:

\footnotetext{
A presença de ministros, autoridades do Executivo e parlamentares no Encontro Nacional da Indústria - ENAI -, realizado pela CNI esta semana, em Brasília, serviu para mostrar que é possível unir os esforços do governo e da iniciativa privada na minimização dos efeitos da crise internacional sobre a economia brasileira.

A CNI construiu uma Agenda Emergencial, logicamente sem abandonar a Agenda Estrutural que já vem sendo trabalhada. As propostas, no entanto, precisam seguir uma trajetória essencial que se divide em dois pontos: as autoridades têm que ser receptivos à realidade das empresas privadas, admitindo as sugestões apresentadas; e as propostas, quando transformadas em medidas de governo, devem chegar efetivamente aos seus destinatários (TIGRE, 2008).
}

Em 2009, a mobilização para o IV ENAI, realizado nos dias 17 e 18 de novembro, foi iniciada ainda no mês de julho. A própria CNI construiu uma agenda preparatória, mobilizando 
os sindicatos industriais (até o dia 15 de agosto) para que apresentassem sugestões para o encontro nacional e estabelecendo um período de inscrição para o evento (do dia primeiro de setembro até o dia 02 de outubro) (FIERGS, 2009a). A FIERGS, no dia 20 de outubro, realizou o Encontro Estadual com dirigentes de Sindicatos de Indústrias no Rio Grande do Sul, para discutir "fatores que afetam a competitividade nos negócios e definir as prioridades setoriais e regionais", já num trabalho preparatório para o IV ENAI, mas, também, atendendo uma solicitação da CNI que, naquele momento, já iniciava sua articulação visando as eleições presidenciais de 2010 (a CNI definiu uma “Agenda Política 2010”, que foi entregue aos candidatos à Presidência da República, em 2010).

Ao final daquele Encontro Estadual, as lideranças da burguesia industrial no Rio Grande do Sul publicaram uma “Carta da Indústria do RS" que traduzia os pontos consensados naquele Encontro (importância de investimentos em inovação; redução dos fatores de custos estaduais, em especial vinculados às áreas tributárias, logística e de infraestrutura; maior facilidade no acesso ao crédito; programas setoriais focados; desburocratização) e, inclusive, indicava medidas governamentais pontuais, consideradas necessárias para impulsionar a indústria sulrio-grandense: regulação de Lei Estadual da Inovação; manutenção das obras do PAC (Programa de Aceleração do Crescimento); políticas industriais favoráveis ao aproveitamento de oportunidades decorrente do Pré-Sal; extinção do piso salarial regional; articulação para obras de infraestrutura relacionadas à Copa do Mundo de 2014; prorrogação por dois anos dos programas do BNDES com vencimento previsto para 31 de dezembro; redução da carga tributária no setor elétrico; melhorias e adequações regionais na legislação ambiental; desoneração das exportações; análise da política cambial então vigente, com medidas diretas ou compensatórias para o setor exportador (FIERGS, 2009b). Com esses pontos e essas propostas, 62 lideranças industriais participaram do IV ENAI, num evento que, naquela edição, teve uma motivação especial, pois antecedia um ano eleitoral. Nesse sentido, o presidente da FIERGS sintetizava: “o objetivo é comprometer os políticos candidatos em 2010 aos governos estaduais, nos legislativos e à Presidência da República com uma plataforma de questões para o desenvolvimento do segmento privado" (FIERGS, 2009c).

Por fim, no último ano do segundo governo Lula, em 2010, a CNI organizou o V ENAI, realizado em São Paulo, nos dias $1^{\circ}$ e 02 de dezembro daquele ano, com o tema "Olhando o Futuro - o desafio da competitividade para a indústria brasileira". A FIERGS manteve a mobilização já realizada nos anos anteriores: orientou a reflexão no Rio Grande do Sul a partir dos pontos que a própria CNI definiu como prioritários para aquele encontro (tributação, gasto público e financiamento, micro e pequenas empresas, desburocratização do ambiente de 
negócios no Brasil, investimentos em infraestrutura, inovação e regulação do meio ambiente) e participou com uma comitiva formada por 63 lideranças industriais (FIERGS, 2010).

O registro das mobilizações organizadas pela FIERGS com o objetivo de preparar a participação dos industriais gaúchos nos ENAIs durante o segundo governo Lula já permite identificar alguns elementos importantes e relacionados à capacidade de articulação classista da burguesia industrial. Durante aquele período, os encontros nacionais promovidos pela burguesia industrial foram eventos que mobilizaram lideranças industriais, industriais de diferentes segmentos e regiões, sindicatos, federações e a própria CNI.

Como afirma Edward Thompson, a classe não se define, por si só, a partir de estruturas objetivas, mas se organiza (e se desorganiza) enquanto vive sua própria história (THOMPSON, 1987, p. 10). É nesse sentido que a classe é uma relação: uma relação histórica, pois se forma a partir de suas próprias experiências de luta, de organização e de mobilização; uma relação com outras classes, pois as classes constroem identidades nas lutas que estabelecem entre si; uma relação na classe, pois o "fazer-se classe" implica um processo de construção de identidades políticas, ideológicas entre indivíduos e grupos que compartilham experiências comuns, condicionadas essas (mas não estruturadas) pelas posições que ocupam no conjunto de relações sociais de produção constituintes de uma determinada formação social e histórica (IDEM, Ibid., p. 10).

No "fazer-se classe", a capacidade de articulação intraclasse é fundamental, pois permite afirmar concepções políticas e ideológicas, articular formas coletivas de ação/reação, estabelecer formas de intervenção sociopolíticas nas instâncias de decisão presentes na sociedade e no estado. Claro que a capacidade de articulação intraclasse é condicionada pela capacidade estrutural da classe. Assim, por exemplo, setores competitivos num ambiente de abertura econômica podem se diferenciar, em termos de construção de identidades políticas e ideológicas, de setores não competitivos em situações de definição coletiva quanto a modelos de inserção econômica de uma região (subnacional ou, mesmo, nacional) onde atuam. A capacidade estrutural de classe, nesse sentido, pode colocar-se como elemento de seleção em processos de construção da capacidade intraclasse: as diferenças em termos de tamanho das indústrias, setores industriais (e a posição dos mesmos no contexto da reestruturação capitalista) etc., podem resultar em maior ou menor intensidade de processos de construção de identidades políticas da classe em momentos de lutas pela defesa de interesses politicamente consensados.

Contudo, a capacidade intraclasse pode ser intensificada através da capacidade organizacional da classe. Isso significa que a capacidade de auto-organização da classe varia de acordo com a capacidade de articulação consciente que as instituições representativas, as 
lideranças, as estratégias adotadas de mobilização e de organização conseguirem estabelecer entre os seus membros. A capacidade organizacional da classe, nesse sentido, pode ser um importante elemento para amenizar (e, mesmo, anular) as diferenças em termos de capacidade estrutural de classe num processo de auto-organização de classe.

Essas definições são importantes para a compreensão do processo de formação de classe da burguesia industrial. Se tomarmos o caso específico da burguesia industrial no Rio Grande do Sul, é claro que a própria estrutura industrial no território gaúcho comporta diferentes tamanhos de indústrias, diferentes setores que podem expressar também diferentes formas de inserção econômica na dinâmica do capitalismo no Brasil e, mesmo, no processo de mundialização do capital. A heterogeneidade de interesses, não somente resultante de posições diferenciadas na estrutura econômica, é constituinte da formação de classe da burguesia industrial. Contudo, a constatação de heterogeneidades não pode relativizar a capacidade dessa fração da burguesia brasileira de atuar como força social e coletivamente mobilizada em defesa de seus interesses de classe, posicionando-se em favor de determinadas direções e projetos históricos na dinâmica de desenvolvimento do capitalismo no País e contra direções e projetos defendidos por forças sociais e políticas identificadas como antagônicas aos seus interesses de classe.

É nessa direção que a mobilização política impulsionada pelos Encontros Nacionais tem grande importância. No caso do Rio Grande do Sul, durante o segundo governo Lula esse evento nacional proporcionou espaços de debates e de reflexões (no interior da burguesia industrial) acerca das condições de desenvolvimento da indústria e da economia sul-riograndense, a identificação de pautas de reinvindicações para os governos (estadual e nacional), a construção de agendas políticas que traduziam consensos possíveis e construídos a partir das articulações políticas efetivadas, a aproximação política e ideológica com instituições representativas de outros estados da federação e com a entidade maior de representação dos interesses da burguesia industrial no Brasil: a CNI. Naquele processo de articulação política, a burguesia industrial "visualizou objetivos globais", traduzidos em agendas políticas que se constituíram a partir de cada um dos encontros realizados, e operacionalizou ações visando efetivar aquelas agendas.

\section{A "Agenda" da burguesia industrial no Brasil durante o segundo governo de Luís Inácio Lula da Silva}

Embora o objetivo deste artigo seja analisar como os Encontros Nacionais da Indústria realizados durante o segundo governo Lula expressaram um processo de articulação classista 
da burguesia industrial, impulsionando, inclusive, mobilizações políticas entre os segmentos regionais dessa fração da burguesia no Brasil, é importante registrar, também, aspectos da agenda política construída a partir daqueles eventos.

Os ENAIs realizados durante o segundo governo Lula proporcionaram amplas reflexões políticas e ideológicas, construídas não somente a partir da preparação articulada pela CNI e pelas federações estaduais da indústria, mas, também, com a participação de intelectuais, de lideranças políticas do País, de membros do executivo e do legislativo (Ministros de Estado, Deputados Federais, Senadores da República). Ao final de cada encontro, a CNI publicizou "Cartas da Indústria" que, embora não traduzissem todos os debates e todas as contribuições que aqueles eventos produziram, sintetizavam os pontos principais de uma agenda política.

Assim, por exemplo, a "Carta da Indústria” resultante do II ENAI (2007) recebeu o título "Sustentabilidade do Crescimento" e expressou a expectativa positiva da burguesia industrial em relação à dinâmica econômica do País naquele momento (início do segundo governo Lula), enfatizando a necessidade de aquela dinâmica ser sustentada. Nessa direção, a "Carta" destacou avanços alcançados no primeiro governo Lula (condições favoráveis de financiamento da economia, em função da queda nas taxas de juros e da redução do spread bancário; apoio à inovação, através de políticas de capacitação tecnológica das empresas, de um marco regulatório favorável e de mecanismos de fomento; "pequenos avanços na universalização do ensino básico de qualidade”; política comercial adequada à promoção das exportações), identificou "áreas sem avanço" (flexibilização da legislação trabalhista, desburocratização, infraestrutura, meio ambiente, dificuldades do PAC - Programa de Aceleração do Crescimento resolver problemas de infraestrutura) e, inclusive, acusou "retrocessos": "a gestão dos gastos públicos e o objetivo da redução da carga tributária foram apontados pela maioria dos empresários como áreas em que houve retrocesso" (CNI, 2007). Assinalou, ainda, alguns pontos de uma agenda política que, no entendimento da burguesia industrial, deveria orientar as ações do executivo, do legislativo, do judiciário, das organizações empresariais e dos trabalhadores e das "demais entidades da sociedade civil", num "esforço coletivo" ("é momento de união", diz a "Carta") em favor da "sustentabilidade do crescimento": a reforma tributária, a redução dos gastos públicos, a reforma da previdência, a solução para os problemas de infraestrutura no País, a consolidação de marcos regulatórios "adequados", com "agências independentes e uma maior segurança jurídica". Por fim, as lideranças da burguesia industrial no Brasil afirmaram, através daquela "Carta", o papel de vanguarda historicamente assumido pela indústria na sociedade brasileira (a "Carta" cita a participação da Sociedade Auxiliadora da Indústria Nacional em defesa da abolição da escravatura; o Movimento dos Oito 
e o Fórum dos Líderes, na década de 1970, "na luta pela democracia”), destacando-se a decisão tomada no II ENAI de "desenvolver um conjunto de iniciativas voltadas para o fortalecimento associativo e para a modernização das entidades de representação da indústria” (IDEM, Ibid.)

Já a "Carta da Indústria” do III ENAI, realizado em 2008, expressou as preocupações da burguesia industrial no Brasil com a "crise econômica internacional de 2008", que se manifestou mais intensamente na economia norte-americana, mas que se refletiu em toda a economia mundial. A "Carta" inicia registrando a situação favorável da economia brasileira naquela conjuntura, chamando a atenção, no entanto, para a crise econômica internacional e para a necessidade do País "minimizar os impactos e construir uma agenda que reforce as forças estabilizadoras e garanta a continuidade do processo de transformação da economia" (IDEM, 2008). Destaca que as "falhas de coordenação e supervisão, que permitiram a supervalorização de ativos nos mercados mundiais e a ocorrência de uma recessão global, não significam o fracasso da livre iniciativa e da capacidade do setor privado em liderar o processo de crescimento" (IDEM, Ibid.), repudiando qualquer possibilidade de um "intervencionismo permanente do Estado". Nessa direção, a "Carta" propõe quatro princípios que, no entendimento da burguesia industrial, deveriam orientar a política econômica do governo naquele momento: 1. Manter o ambiente macroeconômico estável e seguro; 2. Respeitar os fundamentos da economia de mercado; 3 . Reduzir as incertezas regulatórias para investimentos produtivos; 4. Focar na competitividade sistêmica da economia (CNI, 2008). A partir desses princípios, então, a "Carta" sugere uma "agenda pró-produção e emprego", visando criar mecanismos de proteção da economia nacional diante da crise econômica internacional e garantir a continuidade do período de crescimento. A "agenda pró-produção e emprego" sugerida foi dividida em dois grupos de ações: as "ações emergenciais" e as "ações estruturantes". Entre as ações emergenciais, a burguesia industrial sugeria: 1. Ampliar, "em caráter excepcional", o prazo de recolhimento dos tributos; 2. Facilitar a compensação de créditos tributários federais no pagamento de contribuições do INSS; 3. Reduzir as alíquotas do Imposto sobre Operações Financeiras (IOF) nas operações de crédito; 4. Disciplinar a utilização das reservas internacionais, assegurando linhas de financiamento para as empresas exportadoras; 5. Adequar as linhas de financiamento para exportação de acordo com as necessidades das empresas exportadoras. E entre as ações estruturantes, as sugestões eram: 1. Questão tributária, com reforma, diminuição da carga, desburocratização e desoneração dos investimentos e das exportações; 2. Privilegiar os gastos públicos em financiamentos, em especial em infraestrutura; 3. Reduzir encargos e a "insegurança jurídica nos contratos de trabalho"; 4. Melhorar a logística e avançar no aperfeiçoamento dos marcos regulatórios; 5. 
Promover uma agenda de produtividade e de inovação; 6. Aperfeiçoar o marco regulatório do meio ambiente de modo a favorecer aos investimentos privados (IDEM, Ibid.).

A “Carta da Indústria” do IV ENAI, realizado em 2009, inicia indicando a preocupação com "obstáculos que reduzem o potencial de crescimento do País" e com a necessidade de se identificar as "competências que o Brasil precisa desenvolver para construir uma moderna economia de mercado com inclusão social e sustentabilidade ambiental” (IDEM, 2009). Demonstrando uma avaliação positiva da dinâmica da economia brasileira naquela conjuntura, a burguesia industrial apostava: "é possível criar as condições para o País crescer a uma taxa média de 6\% a.a." (IDEM, Ibid.). Nessa direção, enfatizou a necessidade de uma política industrial capaz de garantir o desenvolvimento do parque industrial no País (repudiando, inclusive, visões contrárias) e propôs uma agenda, dividida em "ações de curto prazo" (que deveriam ser executadas ainda no governo Lula) e "ações de longo prazo" (que definiam o que a burguesia industrial entendia dever ser prioridade para o próximo governo nacional). Entre as "ações de curto prazo": 1. Desonerar os investimentos; 2. Aperfeiçoar a política cambial, evitando valorização excessiva do Real; 3. Avançar na redução do custo do capital e do spread bancário; 4. Priorizar os gastos públicos em infraestrutura e evitar o crescimento dos gastos correntes; 5. Aperfeiçoar o marco regulatório do meio ambiente; 6. Apoiar processos de inovação; 7. Desenvolver marcos regulatórios favoráveis aos investimentos privados; 8. Assegurar a autonomia e a eficiência das agências reguladoras; 9. Desburocratizar o comércio exterior; 10. Evitar normas e leis que gerem custos sobre as empresas e sobre o emprego; 11. Regularizar a terceirização; 12. Limitar o uso da substituição tributária (CNI, 2009). E entre as "ações de longo prazo" que, afinal, definiam as expectativas em relação ao governo que substituiria o governo Lula, a "Carta" assinalava que "novo governo não significa a destruição dos ativos desenvolvidos pelo anterior" e sugeria: 1. Elevar a qualidade da educação; 2. Aperfeiçoar o sistema tributário; 3. Aumentar a capacidade de investimento do Estado em infraestrutura e fortalecer os marcos capazes de atrair o investimento privado; 4. Impulsionar a inovação nas empresas industriais; 5. Desenvolver estratégia industrial para uma economia de baixo carbono; 6. Fazer a reforma da previdência; 7. Racionalizar os gastos públicos, com redução dos gastos correntes e priorização nos investimentos em infraestrutura; 8. Avançar na profissionalização da administração pública na busca de maior eficiência do Estado; 9. Modernizar o sistema de relações de trabalho; 10. Fortalecer a qualidade e a independência dos órgãos regulatórios; 11. Avançar na modernização das instituições financeiras e na elevação do seu papel como financiador do setor produtivo; 12. Desburocratizar a economia; 13. 
Desenvolver acordos comerciais capazes de ampliar o acesso a mercados e a fortalecer a estratégia industrial do País; 13. Modernizar as instituições políticas (IDEM, 2009).

Enfim, ao final do governo Lula, a posição hegemônica da burguesia industrial afirmava a necessidade de continuidade dos "ativos desenvolvidos" por aquele governo e apresentava, para o futuro governo, uma agenda definida a partir de 13 ações. Nessa direção, inclusive, a "Carta" de 2009 finalizou afirmando a confiança da burguesia industrial no próximo governo, no sentido de garantir a estabilidade macroeconômica, respeitar "os fundamentos de uma economia de mercado" e "mitigar as incertezas regulatórias" e, já com vistas para as eleições de 2010, remeteu um recado para os candidatos naquelas eleições (tanto para o Executivo quanto para o legislativo), com uma clareza irreparável:

\begin{abstract}
A existência de eleições em 2010 é uma oportunidade para que o Brasil se concentre no que é essencial para crescer mais e melhor. A indústria apresentou no $4^{\circ}$ ENAI as suas primeiras ideias sobre o que deverá ser a agenda do próximo governo. Nos próximos meses aprofundará essa discussão e buscará construir as alianças políticas capazes de implementar essa agenda (CNI, 2009).
\end{abstract}

Por fim, a "Carta da Indústria" do V ENAI, realizado em 2010, já num período posterior à eleição de Dilma Rousseff para a Presidência da República, teve como título "Competitividade Brasil. A hora é essa" e destacou a importância de uma agenda de competividade para o Brasil. A "Carta" reconheceu os "avanços importantes na estabilização, na sustentação do crescimento econômico e na distribuição de renda com inclusão social" (IDEM, 2010b) e conclamou para uma "parceria estratégica entre o governo e setor privado para a agenda da competividade" (IDEM, Ibid.). Alegando serem maiores os riscos para a estrutura industrial do País em caso da não realização de "reformas pró-competitividade", a Carta reafirmou "prioridades" já indicadas nos anos anteriores: aumentar a capacidade do Estado investir, atrair capitais privados para a infraestrutura, resolver as distorções do sistema tributário, reduzir as incertezas jurídicas e custos do sistema de relações de trabalho, avançar “mais rapidamente" nas agendas da educação e da inovação (IDEM, Ibid.).

Ainda que descritivo, o registro das Cartas da Indústria resultantes dos ENAIs realizados pela burguesia industrial durante o segundo governo Lula ganha importância por diferentes motivos.

Em primeiro lugar, é expressão de uma ampla mobilização política que, como já assinalado neste artigo, envolveu não somente as lideranças da CNI, mas, também, as lideranças industriais em todos os estados da federação, mais intelectuais e lideranças políticas que 
contribuíram para as discussões realizadas na construção das agendas políticas da burguesia industrial naquele período.

Em segundo lugar, as "Cartas da Indústria" sintetizam as agendas políticas da burguesia industrial no período analisado. De forma clara, as "Cartas", em todos os anos investigados, apresentam propostas que visam resolver questões conjunturais, mas, também, propostas que definiam as "prioridades estruturais" da burguesia industrial naquele período. Nesse sentido, a "agenda estrutural" da burguesia industrial durante o segundo governo Lula, expressão de consensos estabelecidos nos encontros nacionais, contemplava: reforma tributária, numa perspectiva de redução da carga tributária do País; "racionalização" dos serviços e dos gastos públicos, de forma a priorizar os gastos com investimentos, em especial em infraestrutura; reforma da previdência social; definição de marcos regulatórios adequados, garantindo-se segurança aos investimentos privados; "modernizar" as relações de trabalho, numa perspectiva de flexibilização da legislação trabalhista, de redução dos encargos e de redução do que era entendido como "insegurança jurídica nos contratos de trabalho"; investimentos na educação, em especial na educação básica; políticas de incentivo à inovação nas empresas privadas; "modernização" das instituições financeiras, visando "elevar seu papel como financiadoras do setor produtivo"; desburocratização da economia; política comercial favorável à produção industrial realizada no País.

Em terceiro lugar, essa agenda política consensada nos encontros nacionais tornou-se um importante instrumento de pressão política junto às autoridades governamentais, nas pressões realizadas no Congresso Nacional, na própria definição de estratégias de apoio político nas eleições. Todos os encontros, mais do que as "Cartas" produziram documentos que sustentaram uma "agenda da indústria" no período. A título de exemplo, no V ENAI, realizado em 2010, a burguesia industrial produziu uma "Carta aos Presidenciáveis", um documento com 238 páginas apresentando e argumentando em favor de uma "agenda da indústria" (CNI, 2010a), que foi apresentado e discutido com os candidatos à Presidência da República que foram ao segundo turno: Dilma Rousseff (Partido dos Trabalhadores) e José Serra (Partido da Social Democracia Brasileira). Além disso, como a própria "Carta da Indústria” de 2010 deixou claro, a agenda política construída nos encontros serviu de referência para a discussão de apoio político a candidatos, tanto do executivo quanto do legislativo.

Por fim, e não menos importante, as "Cartas da Indústria" do período que compreendeu o segundo governo Lula traduzem uma visão hegemônica na burguesia industrial em relação àquele governo. Embora todas as "Cartas" daquele período apontem pontos críticos no governo, o que se destaca é o reconhecimento da positividade da política econômica executada pelo 
governo Lula, inclusive no que diz respeito à proteção da economia do País na crise econômica internacional de 2008/2009. Não é possível nos limites deste artigo explorar com maiores detalhes esse "reconhecimento" da burguesia industrial em relação ao segundo governo Lula. De qualquer forma, considerando que, em 1989, “oitocentos mil empresários iam embora do País" se Lula ganhasse as eleições para Presidente da República, ${ }^{2}$ e considerando que, na década de 1990, Lula foi a principal liderança das forças sociais e políticas que se opuseram ao projeto neoliberal de reestruturação do capitalismo no País (projeto amplamente apoiado pela burguesia industrial), as manifestações da burguesia industrial, expressas nas "Cartas da Indústria" durante o segundo governo Lula, diziam, claramente, que alguma coisa tinha mudado abaixo da linha do equador.

\section{Conclusões:}

A atuação política da burguesia industrial enquanto força social e coletivamente organizada não deve ser tomada como um dado. Antes, pelo contrário, sua capacidade de atuação classista precisa ser tomada como problema, como um processo a ser investigado. Uma classe não existe como uma entidade abstrata, com consciência e capacidade de atuação mecanicamente definidas a partir da posição que indivíduos e grupos ocupam no conjunto das relações sociais de produção numa determinada sociedade. É preciso, nesse sentido, desvendar as condições a partir das quais indivíduos e grupos compartilham interesses, formam uma consciência coletiva em torno desses interesses, atuam como força social e coletivamente organizada.

Neste artigo, a análise da participação da burguesia industrial no Rio Grande do Sul nos Encontros Nacionais da Indústria, realizados durante o segundo governo Lula, permitiu perceber a importância que as instituições de representação dos interesses da burguesia industrial no Brasil (em especial, as federações estaduais e a CNI) têm na articulação classista do segmento. A FIERGS e a CNI, na conjuntura analisada, atuaram como "agentes coletivos", espaço-tempo de atuação das elites orgânicas da burguesia industrial, visualizando objetivos estratégicos e táticos na conjuntura analisada, intervindo no interior da classe, construindo hegemonias em torno de uma agenda política, regulando relações divergentes; mas, também, operacionalizando os objetivos de classe e viabilizando a inserção política e ideológica da

\footnotetext{
${ }^{2}$ Em 1989, quando Luís Inácio Lula da Silva disputou o segundo turno das eleições presidenciais com Fernando Collor de Melo, o então presidente da FIESP - Federação das Indústrias do Estado de São Paulo, industrial Mário Amato, afirmou que se Lula ganhasse as eleições, oitocentos mil empresários iam embora do País (CADONÁ, 2012).
} 
classe, com o interesse de tornar seus projetos particulares classistas em demandas gerais, "sociais", de governo, da "Nação".

Demonstraram, assim, serem "associações empresariais de maior abrangência e capazes de organizar a ação coletiva" da burguesia industrial, viabilizando uma ação conjunta em torno de objetivos comuns. Nessa direção, durante o segundo governo Lula indicaram as linhas gerais de avaliação daquele governo, assinalaram as críticas pontuais às políticas governamentais, sugeriram ações para enfrentar questões conjunturais e, acima de tudo, insistiram numa "agenda estrutural" de reformas neoliberais que, desde a década de 1990, define as linhas principais das concepções políticas e ideológicas da burguesia industrial no Brasil.

\title{
NATIONAL INDUSTRY MEETINGS: THE INDUSTRIAL BOURGEOISIE COLLECTIVELY ORGANIZED AND ACTING AS SOCIAL POWER
}

\begin{abstract}
One of the points of disagreement showed in the bibliography that analyses the political action of the Brazilian industrial bourgeoisie after the country's democratization (1980) is linked to the capacity the political leaders, who belong to this slice of the country's bourgeoisie, have in binding the complexity of the industrial interests around the common political agenda. In this paper, the mobilization of the Federation of Industries of the State of Rio Grande do Sul (FIERGS) aiming the participation on the National Industry Meetings promoted by the National Confederation of Industry, during Lula's second term (2007-2010), is taken as a empirical reference for the analyses of the political capacity the entities that represent the Brazilian industrial bourgeoisie have shown in order to bind the segment as collectively organized and acting as a social power, besides make it feasible to joint actions over common goals.

Keywords: Industrial bourgeoisie in the Rio Grande do Sul state, classist action, National Industry Meetings.

\section{Las reuniones nacionales de la Industria (ENAIs): la burguesía industrial actuando como fuerza social y colectivamente organizada.}

\begin{abstract}
Resumen
En la literatura que analiza la actividad política de la burguesía industrial en Brasil de la democratización del país (1980), uno de los puntos de desacuerdo se relaciona con la capacidad de los líderes políticos de la facción burgués en el país para reunir a la complejidad de los intereses industriales en torno de una agenda política común. En este artículo, la movilización de la Federación de Industrias de Rio Grande do Sul, con miras a la participación en reuniones nacionales Industria promovidas por la Confederación Nacional de la Industria durante el segundo gobierno de Lula (2007-2010), se toma como referencia empírica para el análisis de la capacidad política que las entidades de representación burguesía industrial en Brasil han demostrado para unirse al segmento como una fuerza social y colectivamente organizado y facilitar la acción conjunta en torno a objetivos comunes .
\end{abstract}




\section{REFERÊNCIAS}

CADONA, Marco André. A inserção neoliberal: burguesia industrial e a inserção econômica do Rio Grande do Sul no processo de reestruturação do capitalismo no Brasil durante os anos 1990. Florianópolis: UFSC - Programa de Pós-Graduação em Sociologia Política, 2009. (Tese de Doutorado em Sociologia Política).

Burguesia industrial no Rio Grande do Sul e o governo LULA: os posicionamentos políticos da FIERGS (Federação das Indústrias do Estado do Rio Grande do Sul) em relação ao primeiro governo de Luís Inácio Lula da Silva (2002 a 2006). Santa Cruz do Sul: UNISC, 2012. (Relatório de Pesquisa).

CONFEDERAÇÃO NACIONAL DA INDÚSTRIA (CNI). A indústria e o Brasil: uma agenda para crescer mais e melhor. Brasília: CNI, 2010a.

Carta da Indústria: $2^{\circ}$ Encontro Nacional da Indústria. Brasília: CNI, 2007. Disponível em: www.cni.org.br. Acessado em 10 nov. 2013.

Carta da Indústria: $3^{\circ}$ Encontro Nacional da Indústria. Brasília: CNI, 2008. Disponível em: www.cni.org.br. Acessado em 10 nov. 2013.

Carta da Indústria: $5^{\circ}$ Encontro Nacional da Indústria. Brasília: CNI, 2010b. disponível em: www.cni.org.br. Acessado em 10 nov. 2013.

$4^{\circ}$ Encontro Nacional da Indústria: Carta da Indústria. Brasília: CNI, 2009. Disponível em: www.cni.org.br. Acessado em 10 nov. 2013.

DINIZ, Eli; BOSCHI, Renato. Empresários, interesses e mercado: dilemas do desenvolvimento no Brasil. Belo Horizonte: UFMG, 2004.

DINIZ, Eli; PEREIRA, Luiz Carlos Bresser. Depois do consenso neoliberal, o retorno dos empresários industriais? Disponível em: http://www.bresserpereira.org.br/papers/2007/07.03.Empres\%C3\%A1riosEliDinizBresserPer eira.9Outubro07.pdf. Acesso em: 25 out. 2013.

DREIFUSS, René. A internacional capitalista: estratégias e táticas do empresariado transnacional (1918 - 1986). Rio de Janeiro: Espaço e Tempo, 1986.

FARIA, Camila G. M. de \& MELO, Alessandro de. O pacto social como princípio orientador da visão de sociedade da burguesia industrial brasileira. VII Congresso Latino-Americano de Estudos do Trabalho. O trabalho no século XXI. Mudanças, impactos e perspectivas. In: http://www.congressoalast.com/wp-content/uploads/2013/08/130.pdf. Acesso em: 17 out. 2013.

FIERGS (Federação das Indústrias do Estado do Rio Grande do Sul). Agenda do Encontro Nacional da Indústria. Semana, Porto Alegre, n. 29, ano XIV, 24 de julho de 2009a. In: www.fiergs.org.br. Acesso em: 04 nov. 2013.

Encontro Estadual define posição da FIERGS para o II Enai. Semana, Porto Alegre, n. 40, ano XII, 5 de outubro de 2007b. In: www.fiergs.org.br. Acesso em: 30 out. 2013.

Encontro nacional debate prioridades para o desenvolvimento. Semana, Porto Alegre, n. 48, ano XV, 03 de dezembro de 2010. In: www.fiergs.org.br. Acesso em: 04 nov. 2013. 
Fórum dos vice-presidentes. Semana, Porto Alegre, n. 46, ano XIII, 16 de novembro de 2007d. In: www.fiergs.org.br. Acesso em: 30 out. 2013.

Fórum dos vices regionais debate II Enai. Semana, Porto Alegre, n. 38, ano XII, 21 de setembro de 2007a. In: www.fiergs.org.br. Acesso em: 30 out. 2013.

Indústria analisa propostas para o crescimento do RS. Semana, Porto Alegre, n. 35, ano XIII, 29 de agosto de 2008. In: www.fiergs.org.br. Acesso em: 01 nov. 2013.

Indústria alerta que Brasil precisa manter crescimento. Semana, Porto Alegre, n. 43, ano XII, 26 de outubro de 2007c. In: www.fiergs.org.br. Acesso em: 30 out. 2013.

Setor industrial elege a inovação como prioridade. Semana, Porto Alegre, n. 42, ano XIV, 23 de setembro de 2009b. In: www.fiergs.org.br. Acesso em: 04 nov. 2013.

Setor industrial encaminha prioridades em Brasília. Semana, Porto Alegre, n.46, ano XIV, 20 de novembro de 2009c. In: www.fiergs.org.br. Acesso em: 04 nov. 2013.

MANCUSO, Wagner P.; OLIVEIRA, Amâncio J. Abertura econômica, empresariado e política: os planos doméstico e internacional. Lua Nova, São Paulo, v. 69, p. 147-172, 2006.

TIGRE, Paulo F. Encontro de ideias. FIERGS. Semana, n. 36, ano XII, 06 de setembro de 2007. In: www.fiergs.org.br. Acesso em: 01 nov. 2013.

Uma agenda emergencial. FIERGS. Semana, n. 44, ano XIII, 31 de outubro de 2008. In: www.fiergs.org.br. Acesso em: 01 nov. 2013.

THOMPSON, Edward P. A formação da classe operária inglesa - a árvore da liberdade. Trad. de Denise Bottmann. Rio de Janeiro: Paz e Terra, 1987. v. 1.

Data de recebimento: 08/03/15

Data de aceite: $27 / 07 / 16$

\section{Sobre o autor:}

Marco André Cadoná é Graduado em Filosofia, com Mestrado em Sociologia e Doutorado em Sociologia Política. É professor na UNISC - Universidade de Santa Cruz do Sul, onde atua na graduação e no Programa de Pós-Graduação (Mestrado e Doutorado) em Desenvolvimento Regional. E-mail: mcadona@unisc.br 